\title{
Entre movimiento y partido: la transformación del republicanismo francés de mediados del siglo XIX
}

Ronald AminZADE

Movimientos sociales: organización formal, institucionalización e ideología

$\mathrm{E}$ xiste desacuerdo entre los académicos acerca del rol de la organización formal e informal en la constitución de un movimiento social. Las teorías basadas en la tradición del comportamiento colectivo enfatizan habitualmente la informalidad, la espontaneidad y las normas emergentes. En esta tradición, los movimientos sociales, como el pánico, el frenesí y los motines, implican un comportamiento relativamente desestructurado e informalmente organizado. "Como colectividad" señalan Ralph Turner y Lewis Killian, "un movimiento es un grupo con una membresía indefinida y variable, con un liderazgo cuya posición es determinada más por la respuesta informal de adherentes que por procedimientos formales de legitimación de la autoridad" (Turner y Killian, 1987: 223). Los teóricos del comportamiento colectivo se caracterizan por reconocer la importancia de la organización formal sólo en las últimas etapas de desarrollo del movimiento. En cambio, con frecuencia los teóricos de la movilización de recursos distinguen los movimientos de otras formas más espontáneas de acción colectiva, enfatizan la organización formal y la planificación (Jenkins, 1983: 528-529). Reconociendo la diversidad de las formas organizacionales y los grados variables de organización formal que

\footnotetext{
* Este texto es la traducción autorizada del artículo original publicado en EE.UU. en un libro colectivo editado por J. Craig Jenkins y Bert Klandermans: The Politics of Social Protest, Comparative perspectives on States and Social Movements, University of Minnesota Press, 1995, capítulo 3: 39-62. Texto traducido por Elisa Campbell y José Manuel León.
} 
atraviesan los movimientos, generalmente éstos enfatizan la importancia de las organizaciones formalmente estructuradas durante todas las fases de desarrollo de un movimiento. El liderazgo, la membresía formal y las reglas formalizadas caracterizan a algunos movimientos, incluso durante su fase emergente (McCarthy y Zald 1973, 1977).

Las características tanto estratégicas como organizacionales han llamado la atención de los teóricos de los movimientos sociales. Un aspecto clave de la mayoría de las definiciones de los movimientos se refiere a su voluntad de adoptar acciones no-convencionales o rupturistas para producir ( $\mathrm{u}$ oponerse) al cambio. En contraste con los partidos políticos y los grupos de presión, los movimientos adoptan acciones políticas no-convencionales y rupturistas. Mark Traugott (1978: 45) sostiene que, al buscar cambiar o reemplazar las estructuras sociales existentes, un movimiento adopta "una postura antiinstitucional" evidenciada por "conductas ilegales tendientes a reconstituir o derribar las estructuras cuestionadas", o por una voluntad de "realizar o idear actos que, de ser exitosos, lleven a una confrontación inevitable con el orden existente". Un movimiento, escribe Alberto Melucci, extiende el conflicto "más allá de los límites de compatibilidad del sistema en cuestión, i.e., rompe con las reglas del juego, destaca objetivos no negociables, cuestiona la legitimidad del poder" (Melucci, 1981: 176). En estas definiciones, lo específico de los movimientos es la voluntad de adoptar formas de acción colectiva no-convencionales, a veces ilegales o revolucionarias. Carentes de conexiones institucionales con las elites políticas y económicas, en vez de trabajar con las estructuras institucionales existentes, los movimientos sociales prefieren las acciones rupturistas. Aunque estas definiciones no necesariamente implican una incompatibilidad entre los movimientos y la acción política institucional, sí destacan la adopción de estrategias no-convencionales o rupturistas como rasgo distintivo de un movimiento social.

Uno de los debates centrales entre los teóricos de los movimientos sociales se refiere a la relación de la estructura organizacional del movimiento con su estrategia. Las preguntas clave son: ¿Acaso los movimientos sociales pierden necesariamente su carácter antiinstitucional al convertirse en organizaciones más formales? ¿Acaso la adopción de estrategias que ponen el acento en la política institucionalizada conduce necesariamente a la organización formal creciente? En síntesis, ¿la estructura organizacional interna de un movimiento tiene necesariamente alguna relación con su estrategia de lucha por el poder?

Siguiendo a Weber y Michels, algunos teóricos de los movimientos sociales han considerado la organización formal y las acciones políticas antiinstitucionales como incompatibles. Por ejemplo, Piven y Cloward argumentan que los esfuerzos de los líderes de los movimientos sociales estadounidenses por construir organizaciones formales perdurables "entorpecen o inhiben la fuerza destructiva que las personas de clase baja son capaces de movilizar en ocasiones" (Cloward y Piven, 1977: xii). Su análisis implica que a medida que los movimientos llegan a estar más formalmente organizados, desvían inevitablemente su energía de la movilización 
de una masa desafiante y se vuelven más complacientes con el statu quo. Los académicos que adoptan la perspectiva del marco evolucionario de un "ciclo de vida" de los movimientos sociales (Lang y Lang, 1961), típicamente tratan la adaptación formal e institucional como dos dimensiones de un mismo proceso. Otros académicos han caracterizado estos procesos como menos entrelazados, documentando casos en los que el desarrollo de una organización formal no conduce a un abandono de las acciones políticas antiinstitucionales ni de las estrategias políticas no-convencionales o ilegales. Así, por ejemplo, el estudio de William Gamson (1975) sobre los movimientos sociales estadounidenses muestra que la organización formal es compatible con la rebelión de las masas y con estrategias de protesta no-convencionales o rupturistas. Su investigación sugiere que el desarrollo de la organización formal y la institucionalización no siempre son procesos complementarios (véase también a Jenkins, 1977, 1985).

Cuando dejamos de considerar la institucionalización y la formalización como parte de un mismo proceso que puede ser graficado como una secuencia única, podemos empezar a explorar las relaciones entre ambas. Esta reconceptualización sugiere que los movimientos y los partidos pueden seguir diferentes trayectorias históricas de desarrollo definidas por estos dos procesos. Estudiando el desarrollo histórico del republicanismo francés de mediados del siglo XIX, de movimiento a partido, este ensayo busca clarificar las relaciones entre formalización e institucionalización en un contexto histórico particular. Este contexto estuvo marcado por cambiantes restricciones al sufragio y a los derechos de asociación y por controversias sobre el significado de la representación política en la cultura política republicana de Francia de mediados del siglo XIX.

Mi investigación histórica contempla las siguientes preguntas: ¿acaso la transformación del republicanismo francés de movimiento a partido implicó el desarrollo de estructuras organizacionales más formales y el rechazo simultáneo de acciones políticas antiinstitucionales a favor de acciones políticas electorales? ¿Siguieron las dimensiones organizacionales y estratégicas de las políticas republicanas francesas líneas paralelas de desarrollo? Por ejemplo, ¿la creciente orientación hacia formas más institucionalizadas de acción política, como las elecciones, estuvo acompañada por un incremento de la formalización? ¿Condujo la formalización a una cooptación y a un abandono de las acciones políticas rupturistas o antiinstitucionales? Si la formalización y la institucionalización no siempre estuvieron estrechamente conectadas, ¿cuáles fueron los determinantes de cada uno de los procesos que ayudan a explicar su divergencia? Más específicamente, ¿cómo una estructura de oportunidades políticas cambiantes y los conflictos sobre el significado de la representación política moldearon cada uno de estos procesos?

Primero, estudio dos características organizacionales clave del republicanismo francés de mediados del siglo XIX: diversidad y localismo. Y señalo que estas características dieron al republicanismo francés inicial un carácter transicional, exhibiendo los rasgos tanto de un partido como de un movimiento, aunque se asemeje más a este último. Luego describo las 
cambiantes orientaciones estratégicas del republicanismo, mostrando que la voluntad de los republicanos de sustentar formas de acción colectiva no-electorales y rupturistas estaba estrechamente ligada a la lucha, en el republicanismo francés, entre la visión participativa y la visión representativa de la democracia. En conclusión, sugiero que, en el caso del republicanismo francés, la formalización e institucionalización no fueron siempre procesos paralelos, debido a que cada uno de ellos fue moldeado por diferentes factores. Aunque la cambiante estructura de oportunidad política -especialmente los cambiantes niveles de represión- jugó un papel clave en la configuración de ambos procesos ${ }^{1}$, el carácter localizado de la política francesa y las reglas del sistema electoral fueron determinantes cruciales de la formalización. La crisis de los regímenes, las experiencias previas con diferentes estrategias y las luchas ideológicas entre los republicanos sobre visiones alternativas de la democracia, jugaron un rol central en la configuración de las estrategias republicanas de competencia por el poder.

\section{Rasgos organizacionales del republicanismo francés de mediados del siglo XIX: diversidad y localismo}

El partido republicano francés no fue una organización única, sino que un agrupamiento de diversas organizaciones dispersas en un amplio espacio. Estas organizaciones se vinculaban de un modo bastante amplio por medio de instituciones coordinadoras, como los periódicos parisinos, voceros itinerantes y líderes parlamentarios electos que viajaban a París cuando el Parlamento sesionaba. A nivel local, el Partido Republicano estaba compuesto por diversas formas enraizadas en una rica herencia organizacional, la cual incluía los clubes jacobinos de la Revolución Francesa, las sociedades conspirativas secretas de la Restauración y centros informales de sociabilidad como los cercles y los cafés (Huard, 1978). Los activistas partidarios locales mantenían vínculos estrechos con los centros informales de sociabilidad. Típicamente los periódicos republicanos conectaban estas redes sociales, estableciendo un pequeño grado de coordinación entre centros de socialización cotidianos, dispersos y manifiestamente no-políticos. "El rol más cercano al de las oficinas, comités y centros de operación de los partidos políticos del siglo XX", observó Maurice Agulhon, "lo jugaron durante el siglo XIX las oficinas editoriales de los periódicos" (Agulhon, 1983: 16).

La importancia de las diferentes formas organizacionales varió según niveles distintos de represión política. La represión intensa reforzaba el

1. Sidney Tarrow (1989: 34) separa el concepto de estructura de oportunidad política en cuatro componentes: el grado de apertura o cierre para acceder al sistema político institucional; la estabilidad o inestabilidad de los alineamientos políticos; la presencia o ausencia de grupos aliados o de apoyo; y las divisiones al interior de la elite o su tolerancia o intolerancia hacia la protesta. Mi énfasis está puesto en el primer componente: la relativa apertura o cierre del sistema político institucional, reflejada en el grado de represión política. 
rol de las sociedades secretas y de los centros informales de sociabilidad, como cafés, bares y cabarets. Los períodos de liberalización política realzaban la importancia de las asociaciones electorales, círculos y clubes populares, e incrementaban las posibilidades para una coordinación centralizada. Durante los períodos de represión intensa, cuando los militantes republicanos tenían mayores probabilidades de encarar la cárcel o el exilio que multas o absoluciones y cuando la existencia del periódico local del partido era amenazada, las redes sociales informales y las sociedades secretas clandestinas adquirieron mayor importancia (Merriman, 1978). Las sociedades secretas tuvieron estructuras organizacionales diferentes de los círculos politizados, comités electorales o clubes. Su orientación clandestina significó cierto énfasis en una disciplina de tipo militar, rituales elaborados y pequeñas células vinculadas de manera autoritaria al liderazgo principal.

La represión política tuvo consecuencias contradictorias. Al debilitar al Partido Republicano nacional y promover la localización, la represión impidió la formalización, convirtiendo los centros informales diarios de sociabilidad y los contactos cara a cara en la base de sustento central de la movilización política. Pero la represión también promovió la formalización a nivel local, ya que las reglas formales de membresía y de participación ayudaron a las organizaciones republicanas a protegerse contra la infiltración de espías e informantes de la policía.

La observación de Anthony Oberschall según la cual "una red de relaciones comunitarias puede ser la base y el caldo de cultivo para el rápido crecimiento de las redes modernas de asociación" (Oberschall, 1973: 123) encuentra una ilustración clara en el caso del republicanismo francés. Esto es especialmente cierto en regiones como la Provence, el Bajo Languedoc, donde las tradiciones culturales de sociabilidad popular proveyeron un fértil caldo de cultivo para crecimiento de asociaciones políticas formales (Huard 1982; Agulhon 1982). El patrón identificado por Oberschall es particularmente evidente en Francia después de 1849, cuando los republicanos ampliaron sus campañas electorales a la campiña francesa, politizando instituciones comunitarias tradicionales como los clubes locales (chambrées), ceremonias comunitarias como las fêtes y los carnavales, y el folclore popular. Los republicanos utilizaron las tradiciones de ayuda mutua y las instituciones de la sociabilidad popular para forjar nuevos patrones de solidaridad política.

La movilización republicana francesa de mediados del siglo XIX estaba basada en lo que los teóricos de los movimientos sociales etiquetaron como "reclutamiento en bloque". Se trata de la incorporación de grupos preexistentes en lugares de trabajo y vecindarios que ya tenían altos grados de identificación grupal y amplias relaciones interpersonales. "El debate político y social tuvo lugar en las localidades e instituciones propias de la sociabilidad de la clase trabajadora", escribió Maurice Agulhon:

"debido a que era adecuado, debido a que era discreto (al menos en cualquier lugar excepto en la taberna) y también para aprovechar una 
particularidad...: estos hombres simples que se reconocían como hermanos eran propensos a las reacciones de grupo y cuando una idea nacía no pasaba mucho tiempo antes de ser aceptada por todos" (Agulhon, 1984: 57).

Aunque estaba orientada hacia la elección de candidatos, la organización del republicanismo de mediados del siglo XIX tenía las características tanto de un movimiento como de un partido. A pesar de una estructura organizacional que se asemeja más a un movimiento social que a la política partidaria contemporánea, los primeros republicanos franceses mantuvieron vínculos institucionalizados con las elites políticas y económicas y compitieron por los puestos electorales, trabajando dentro de los canales institucionales de participación política.

El carácter informal de la organización republicana francesa fue, en gran parte, un resultado de la orientación predominantemente local previa a 1871. Este localismo estuvo reforzado por el hecho que la fuerza electoral republicana era mayor a nivel local urbano, donde los republicanos obtuvieron sus primeras victorias electorales y comenzaron a ejercer importantes funciones políticas. Previo a 1848, los republicanos ganaron elecciones eligiendo oficiales en unidades de la Guardia Nacional urbana, lo que llevó a la disolución de ésta en Lyon, Grenoble, Marsella y Estrasburgo en 1834-35. También obtuvieron mayorías en los concejos municipales de varias ciudades francesas, incluyendo Toulouse, Grenoble y Estrasburgo. Fue a nivel local, donde la vida política implicaba la interacción cara a cara y conexiones personales, que la gente común se aventuró en política, acumulando experiencia progresivamente. Los partidos y los gobiernos locales, los cuales eran más pequeños y menos lejanos que las instituciones estatales centrales, generalmente fueron más accesibles a los intereses y más receptivos a las luchas de la clase trabajadora. También fueron menos permeables a las presiones emitidas por los actores de la clase dominante nacional, a las exigencias de las relaciones internacionales y a los intereses de los administradores del Estado central.

La fuerza republicana a nivel local provino, en gran parte, del hecho que la política local había sido más democrática que la política nacional desde la revolución de 1830. La ley electoral de 1831 concedió el derecho a voto a entre el 20 y el $25 \%$ de los varones franceses mayores de veintiún años en las elecciones municipales, creando quince veces más electores en las elecciones locales que en las elecciones nacionales (Vigier, 1973: 277). Muchos profesionales, almaceneros y prósperos artesanos que no calificaban para votar en las elecciones nacionales porque no pagaban más de doscientos francos en impuestos, participaron en la elección de los líderes de la Guardia Nacional y del concejo municipal. Estos grupos sociales -artesanos, tenderos y profesionales- que jugaron un rol central en la lucha por la reforma del sufragio en 1846-47 y, más generalmente, en la política republicana de mitad del siglo XIX, fueron iniciados a la política electoral en el nivel local. 
A pesar de los esfuerzos de coordinación nacional, que alcanzaron su nivel más alto durante las campañas electorales nacionales (en 1837, 1839,1842 y 1846) y luego disminuyeron, los republicanos franceses no crearon un partido político, en el sentido moderno del término, antes de 1848. Durante la Monarquía de Julio (1830-1848) hubo líderes republicanos nacionalmente reconocidos así como periódicos republicanos con difusión nacional y los republicanos compitieron activamente por los puestos de elección en todas las regiones de Francia. Pero no hubo organización nacional que seleccionara a los candidatos y promoviera la adhesión a una plataforma política consistente. El Partido Nacional era una colección indeterminada de prominentes líderes locales de similar convicción política. La organización nacional del partido se concentró en torno a media docena de prominentes republicanos en la Cámara de Diputados y en torno a quienes se reunían en las oficinas de los dos periódicos republicanos nacionales en París: Le National y La Réforme. La legislación represiva de la Monarquía de Julio, que proscribió incluso el uso del término "republicano", inhibió el desarrollo de una organización partidaria nacional y centralizada. También contribuyó al carácter descentralizado y de indeterminada coordinación, de los partidos políticos, un sistema de transporte y de comunicación pobremente desarrollado.

Después del establecimiento de una república en 1848, los republicanos franceses renovaron sus esfuerzos por crear una organización nacional de partido capaz de coordinar actividades electorales en diferentes localidades. El advenimiento del sufragio masculino universal y la atenuación de las restricciones al derecho de asociación, de reunión y de prensa, animó a los republicanos a organizarse a nivel regional para efectos de la selección de candidatos, la propaganda electoral y la movilización de votantes. El cambio en las leyes electorales en 1848, del scrutin uninominal d'arrondissement, en el cual los votantes elegían un candidato dentro de límites geográficos relativamente estrechos, al scrutin de liste du département, en el cual los electores elegían una lista completa de candidatos dentro de un área geográfica medianamente grande, también fomentó el crecimiento de los partidos políticos. Los republicanos ampliaron progresivamente sus actividades más allá de los centros urbanos, a los cuales habían sido ampliamente limitados hasta antes de 1848, en un esfuerzo por ganar la masa de votantes rurales alejándolos de sus tradicionales lealtades hacia los notables locales.

La primera elección presidencial directa a nivel nacional bajo un régimen de sufragio masculino universal (diciembre de 1848) incentivó la formación de una organización electoral nacional para apoyar la candidatura presidencial de Ledru-Rollin, Solidaridad Republicana. Esta organización, que tenía un comité central en París, estableció delegaciones en 62 de los 86 departamentos franceses. Rápidamente adquirió un total aproximado de más de 30.000 miembros en 353 delegaciones. Preocupada no sólo por ganar elecciones sino también por asegurar un liderazgo administrativo para un nuevo gobierno, Solidaridad Republicana estableció un gabinete en la sombra en París, con varios "ministros", incluyen- 
do a un Ministerio de Asociaciones de Trabajadores y Agricultores (Berenson, 1984). Solidaridad Republicana tuvo una estructura organizacional jerárquica y centralizada, con un Consejo General que nombraba inicialmente a todos los directores locales, quienes posteriormente eran elegidos por los miembros locales y luego aprobados por el consejo (Latta, 1980).

Bajo la dirección de Solidaridad Republicana, organizaciones de partido de base urbana comenzaron a auspiciar comités electorales en distritos rurales donde no había presencia republicana. Los comités electorales republicanos coordinaron las campañas de representantes parlamentarios a escala regional. La organización también facilitó un vínculo más cercano entre los parlamentarios parisinos y los líderes republicanos provinciales. A pesar del carácter jacobino centralizado del partido, la dirección de sus actividades y la selección de sus candidatos continuaron estando localizadas y centradas en el entorno de las oficinas de los periódicos provinciales. En contraste con los partidos políticos "modernos", el comité nacional no distribuyó ningún fondo de campaña a las delegaciones locales, ni imprimió información para los miembros activos del partido. Tampoco reforzó la disciplina partidaria sobre el personal legislativo del partido.

Los esfuerzos por crear un partido republicano nacional y centralizado sucumbieron rápidamente a la represión política. A principios de 1849, el gobierno cerró los cuarteles generales de Solidaridad Republicana, proscribió oficialmente la organización y arrestó a los líderes más importantes. La continua represión inhibió el desarrollo de una estructura de partido centralizada. La dura represión que siguió al golpe de Estado de LuisNapoleón Bonaparte en diciembre de 1851, destruyó temporalmente lo que había quedado del liderazgo y de la organización nacional del Partido Republicano. La permanencia del sufragio masculino universal después del golpe estimuló la continuidad de las actividades electorales locales organizadas por activistas del partido, pero éstos se volvieron más independientes del liderazgo nacional. El nuevo régimen reinstauró los scrutin uninominal d'arrondissement, lo que redujo el tamaño de los distritos electorales y fomentó por lo tanto las actividades electorales localizadas. Durante los años 1850, los republicanos se replegaron en la red social informal de los barrios, lugares de trabajo y cafés que habían servido de base a las antiguas actividades clandestinas, las cuales fueron revividas después de la inauguración de las reformas liberales de la década de 1860. No fue sino hasta la reanimación de las acciones políticas electorales republicanas, a fines de los años 1860, que el liderazgo nacional de partido comenzó nuevamente a coordinar las actividades electorales locales y regionales.

La persistencia del localismo fue menos el resultado de compromisos ideológicos que el producto de una oportunidad política marcada geográficamente por pequeñas unidades de representación y períodos de intensa represión política, así como por una economía nacional caracteri- 
zada por un sistema de transporte y comunicación débilmente desarrollado. Aunque el localismo promovió las organizaciones informales, una variedad de factores estimuló la formalización, incluyendo la necesidad de coordinación cuando las acciones políticas electorales fueron más allá del nivel local, el deseo de limitar el poder de los notables locales en la nominación de los candidatos y de la amenaza que significaban los espías de la policía durante los períodos de mayor represión política. En respuesta a estas fuerzas, la organización republicana se formalizó más hacia mediados de siglo, pero esto no significó ni personal remunerado ni cuotas formales de membresía. Esto significó el desarrollo de procedimientos rutinarios para la selección de candidatos, haciéndolos responsables de los objetivos del partido y organizando elecciones más allá del nivel local. Típicamente, los republicanos socialistas exigieron un proceso más formal de selección de candidatos antes que el control oligárquico informal de los líderes republicanos burgueses locales. Los republicanos compartieron la percepción de la necesidad de una organización formal para movilizar el apoyo electoral a nivel regional y nacional. Además entendieron la necesidad de una organización formal durante los períodos de represión intensa, durante los cuales el cuidadoso monitoreo de la membresía y del liderazgo los protegía contra el peligro de la infiltración de los espías policiales. Pero esta apreciación de las virtudes de la formalización fue de la mano con el deseo de tomarse las calles y hacer uso de acciones políticas antiinstitucionales para exigir o defender la República.

\section{Estrategias republicanas y significados de la representación}

Para comprender las posturas cambiantes de los republicanos respecto a las estrategias de toma del poder estatal, se requiere un análisis de las diferentes visiones de la representación existentes entre los republicanos. Los republicanos franceses tenían en común un mismo compromiso con una forma de gobierno constitucional. Este elemento en común adquirió importancia frente a la acérrima oposición al gobierno republicano de los poderosos miembros de la clase propietaria, la mayoría de los cuales prefería alguna forma de monarquía ${ }^{2}$. Los republicanos también compartían ciertos valores comunes, incluyendo una creencia en el progreso y el racionalismo político, una hostilidad hacia la aristocracia y la monarquía, así como un rechazo a aceptar la tradición como una base legítima de la autoridad política. La mayoría de los republicanos estaba de acuerdo con un programa político que incluía el sufragio masculino universal, libertades civiles, un gobierno parlamentario, una reforma tributaria, educación laica gratuita y servicio militar obligatorio universal, pero diferían respecto a qué estrategia era más apropiada para alcanzar estos

2. A lo largo de la Monarquía de Julio, los propietarios franceses apoyaron fuertemente a los realistas en vez de apoyar a los republicanos. Sobre la postura de los burgueses franceses frente al republicanismo, ver Ponteil, 1968. 
objetivos políticos. Estas diferencias de estrategia estaban ligadas a nociones distintas del significado de la representación política.

El republicanismo promovió la creación de instituciones parlamentarias formadas por representantes regularmente elegidos. Todos los republicanos reconocieron la legitimidad de tales instituciones. Muchos de los socialistas franceses de mediados del siglo XIX las consideraban como prerrequisitos básicos para el socialismo. La breve experiencia republicana de 1848-51, sin embargo, alentó a algunos socialistas que habían apoyado la república, a cuestionar las instituciones representativas. Reflejando su experiencia como representante electo, en junio de 1849, Proudhon escribió:

“Desde que puse un pie en el Sinaí parlamentario, dejé de estar en contacto con las masas; absorto en mi trabajo legislativo, perdí completamente la noción de lo que ocurría. Uno debe vivir en esta cabina de aislamiento llamada Asamblea Nacional para entender cómo aquellos hombres, que son los más ignorantes acerca de las condiciones del país, son casi siempre aquellos que lo representan" (citado en Lequin, 1984: 68).

A pesar de estas reservas por parte de una minoría de líderes socialistas, las instituciones parlamentarias continuaron suscitando un fuerte apoyo en la amplia mayoría de los trabajadores socialistas después de 1848 . Incluso aquellos que simpatizaban con la visión sindicalista de Proudhon, solían concurrir a las urnas en los días de elecciones durante la Segunda República y al final del Segundo Imperio. Pero el compromiso de los socialistas republicanos con las instituciones parlamentarias estaba basado en una noción participativa de la representación y de la democracia que venía del Antiguo Régimen.

La visión socialista republicana de la democracia a mediados del siglo XIX se basó en la noción del mandato imperativo. De acuerdo con este principio, los representantes electos eran delegados que estaban obligados a obedecer los expresos deseos y demandas de sus electores. Esta idea no se originó en Rousseau, sino que puede ser rastreada desde las elecciones de los Estados Generales del Antiguo Régimen. Los delegados de los Estados Generales tenían un mandato no para deliberar sobre asuntos, sino para representar fielmente los deseos de sus electores, expresados en documentos (cahiers) redactados por cada orden en asambleas deliberativas locales y regionales. Cualquier intento por parte de los delegados de usurpar el poder de los electores, tomando la iniciativa o sobrepasando el límite del mandato explícito de los cahiers, era castigado con la destitución y a veces con penas judiciales y pecuniarias $^{3}$. Los delegados de los Estados Generales no eran elegidos mediante un proceso competitivo de elección en el cual los candidatos ofrecieran visiones alternativas sobre las demandas que debían ser presentadas al rey en los cahiers estatales. Eran seleccionados incluso antes

3. La forma y el contenido de los mandatos variaba según las elecciones y las localidades. Los historiadores franceses no concuerdan sobre la libertad que los electores le daban a sus diputados. Véase Soule, 1968: 77-78 y J. Russel Major 1960: 8. 
que los temas y las demandas fueran compilados en los cahiers, por lo tanto la selección de los delegados sobre la base de sus posiciones sobre determinados temas no era posible. La función de los delegados no era representar las visiones de las facciones en competencia al interior del Estado o bailliage, ni deliberar sobre los temas en discusión. Su función consistía en presentar las deliberaciones de su electorado al rey, siguiendo estrictamente las instrucciones contenidas en el cahier (véanse Soule, 1962: 19; Halevi, 1985: 98).

Durante la Revolución Francesa y a lo largo de la primera mitad del siglo XIX, la noción según la cual los representantes electos estaban obligados por mandato era dominante al interior de los círculos republicanos. Los sans-culottes de la Revolución Francesa adoptaron esta visión de la representación como mandato imperativo. El principio fue elaborado en la Constitución de 1793, con la declaración según la cual el gobierno era propiedad del pueblo soberano y los funcionarios sus servidores. Esta noción de representación se vio reflejada en la hostilidad republicana hacia el Poder Ejecutivo y en la oposición de la mayoría de los republicanos a la elección directa del presidente. También se expresó en el lenguaje político republicano de mediados del siglo XIX, en el cual las plataformas escritas de los candidatos eran llamadas mandats. Los republicanos no negaban la necesidad de las instituciones representativas en un país tan grande como Francia, pero consideraban el principio del mandato imperativo como una manera de asegurar el control popular sobre los representantes electos. La concepción de la democracia desde la visión del mandato imperativo fue resumida en la famosa declaración del líder republicano radical Ledru-Rollin en 1841: "Soy su líder, debo seguirlos". El compromiso republicano con el mandato imperativo también fue evidente en 1848, en los numerosos clubes que aparecieron inmediatamente después de la revolución de febrero. La mayoría de los clubes estimó que su función consistía en constituir un foro público para la discusión de los asuntos políticos y ser los vehículos del ejercicio de la presión popular directa sobre los representantes gubernamentales (sobre el movimiento de clubes parisinos, véase Amman, 1975).

La visión de los representantes electos en tanto delegados con obligaciones vinculantes con los votantes que los elegían legitimó las estrategias antiinstitucionales en competencia por el poder estatal. La visión participativa implicaba el derecho de los ciudadanos para tomar acciones políticas colectivas no-electorales si sus representantes no respetaban sus mandatos. Esta visión refrendaba las acciones políticas electorales pero nunca renunció a la necesidad de la acción revolucionaria bajo ciertas circunstancias. Los republicanos socialistas no siempre respetaron el límite entre la acción colectiva institucionalizada y la antiinstitucional. Durante los momentos de agitación, cuando los trabajadores se implicaron en la acción política republicana, como en los períodos siguientes a las revoluciones de 1830, 1848 y 1870, los trabajadores tomaron las calles e hicieron uso de las formas tradicionales no electorales de protesta popular, incluyendo procesiones, manifestacio- 
nes, peticiones, banquetes, charivaris políticos y serenatas, para castigar o presionar a los representantes gubernamentales. En su visión, las tácticas no electorales rupturistas complementaron más que socavaron las acciones políticas electorales.

La visión alternativa liberal republicana de la representación consideraba a los representantes electos como custodios de la nación, no como simples delegados de sus electores. Esta visión fue elaborada durante la Revolución Francesa por el Abate Sièyes. Se trataba de una respuesta a la incompatibilidad de la noción de mandato imperativo con el interés de los diputados del Tercer Estado de constituirse en Asamblea Nacional para representar una voluntad nacional unitaria (Baker, 1987: 46). Los liberales consideraban a los delegados electos como representantes de la nación francesa, no como representantes de los electores de su localidad o región. En consecuencia, los republicanos liberales abogaron por entregar un poder discrecional considerable a los propios representantes sobre sus actividades parlamentarias. Ellos visualizaban la representación como el proceso mediante el cual se confiaba el poder político a una elite acaudalada, educada e ilustrada.

La Constitución de 1789 proclamó la noción liberal de la representación. Prohibía el mandato imperativo, estableciendo que la Asamblea Nacional encarnaba la voluntad de la nación y que "los representantes electos en los departamentos no serían representantes de un departamento en particular sino de la nación completa, y no les sería dada ninguna orden" (Birch, 1971: 46). La monarquía parlamentaria del régimen orleanista (1830-1848) adoptó este mismo principio de representación, proclamando la independencia de los representantes electos respecto al electorado como necesaria para la "soberanía nacional" (Bastid, 1954: 219). Mientras muchos republicanos criticaban la extensa corrupción y la falta de responsabilidad promovida por este sistema de representación, los liberales arguyeron que el mandato imperativo era inaplicable a un electorado numeroso y que podía promover desórdenes populares, al alentar intervenciones fuera del cuerpo parlamentario. Los liberales republicanos también sostuvieron que la democracia directa podía llevar a los representantes a poner los intereses locales por sobre el interés nacional. Al inhibir el compromiso y la negociación entre los legisladores, también se podían producir interminables impasses parlamentarios y, por esa vía, aumentar el poder del Ejecutivo. Las críticas de los republicanos liberales a la visión participativa de la democracia fueron reforzadas por los cambios institucionales inaugurados por la democracia plebiscitaria de Luis Napoleón Bonaparte, durante los años 1850 y 1860. Luis Napoleón fue exitoso en utilizar los plebiscitos y el referéndum para manejar la expresión del apoyo popular. El régimen también instituyó un sistema electoral basado en pequeñas unidades geográficas (le scrutin d'arrondissement), en lugar de las unidades más grandes (départements) preferidas por los liberales, quienes consideraban a los funcionarios electos como representantes de la nación. La corrupción y el patronazgo político, alentados por este sistema, hicieron que muchos republicanos fueran menos adeptos a la democracia directa. 
Las visiones liberal y participativa de la democracia se basaron en principios fraternalistas y en organizaciones que negaron derechos de ciudadanía a las mujeres ${ }^{4}$. Aunque igualmente comprometidas con una forma fraternalista de asociación política que promovía la desigualdad de género, estas nociones alternativas tenían diferentes implicancias para las estrategias de competencia por el poder. Mientras que la noción de representación como mandato imperativo legitimaba la acción colectiva rupturista cuando los representantes electos fueran indiferentes a sus electores, la visión liberal del rol de los funcionarios electos, como representantes con algún grado de independencia respecto de sus electores, cuestionaba la legitimidad de las acciones políticas antiinstitucionales. Los republicanos liberales insistieron en mantener acciones políticas firmemente implantadas dentro de la arena parlamentaria. Defendieron estrategias que enfatizaron el imperio de la ley y renunciaron a la violencia, así como a la acción política colectiva no-electoral.

\section{Las cambiantes estrategias republicanas y las estructuras de oportuni- dad política}

Los republicanos franceses permanecieron divididos, a través del siglo XIX, sobre cuánto y cuándo una estrategia revolucionaria era legítima. El republicanismo nació en medio de un fermento revolucionario; tanto la Primera como la Segunda República se instalaron por medio de una revolución violenta. La Constitución republicana de 1793 garantizaba el derecho a la insurrección "cuando el gobierno violara los derechos del pueblo (Soboul 1975: 315-17)". Durante la primera parte de la década de 1830, los republicanos socialistas de la Sociedad de Derechos del Hombre se dividieron respecto a la cuestión de la violencia revolucionaria. Una facción disidente denunció la renuencia de los líderes a adoptar la violencia revolucionaria. Luego de la represión de 1834-35, muchos republicanos vieron a la insurrección como la única salida posible hacia una república y se unieron a sociedades secretas insurreccionales. La abortada insurrección parisina de 1839, sin embargo, marcó otro momento decisivo, después del cual los republicanos concurrieron masivamente a las mesas de votación. Las amnistías de 1837 y 1840 restauraron la jerarquía del liderazgo republicano. La primera liberó a los líderes encarcelados y la última permitió a los republicanos regresar del exilio desde Inglaterra, Bélgica y Suiza. La encarcelación y el exilio convencieron a

\footnotetext{
4. La fraternidad no fue simplemente una expresión republicana de la comunidad; fue una forma sociocultural de solidaridad y de comunidad de género, que jugó un rol central en la constitución de la organización republicana. El fraternalismo apela a una visión particular de la camaradería y de la autoridad masculina, permitiendo a los republicanos construir la solidaridad entre clases, basada en afinidades ficticias, sea por la vía de definiciones de la virilidad o de rituales de afectividad masculina. Ver el trabajo pionero de Mary Ann Clawson (1989), quien identifica cuatro elementos que definen el fraternalismo como una forma social específica: corporatismo, ceremonial, masculinidad y derecho de propiedad.
} 
muchos líderes que la violencia insurreccional, la cual había incitado a la represión más que al cambio social, ya no era la manera de derrocar un gobierno que había permanecido en el poder por más de una década.

Durante los comienzos de los años 1840, tanto el ala liberal del partido, representada por el periódico Le Nacional, como su ala radical y socialista, representada por La Réforme, rechazaron el insurreccionalismo. Este abandono de la estrategia revolucionaria no significó que los republicanos fueran simplemente a contentarse con competir por los cargos de elección en la altamente restringida arena política de la Monarquía de Julio (1830-1848). Los republicanos complementaron sus actividades electorales con tácticas más destructivas, destinadas a cuestionar la legitimidad de las restricciones existentes al sufragio. Movilizaron a aquellos que no podían votar a través de varias campañas de petición para la reforma del sufragio, en 1840 y 1846, y del banquete de la campaña de 1846-48 por la reforma del sufragio que culminó en la revolución de febrero de 1848.

La voluntad de los republicanos de abandonar la acción revolucionaria a favor de una estrategia electoral estaba enraizada en su creencia en el poder de la política electoral para transformar, fundamentalmente, el carácter de su sociedad. Durante los años 1840, muchos republicanos llegaron a valorar el sufragio masculino universal como la panacea que resolvería los apremiantes problemas económicos y políticos de la nación. Esta creencia en el poder de la política electoral era ampliamente compartida, incluso por aquellos en el lado opuesto del espectro político. "La democracia", proclamaba el periódico legitimista, Gazette de France en 1848, "siempre tiene al comunismo como resultado" (citado en Tudesq, 1964: 1076). Esta suposición de una incompatibilidad entre la política democrática y el capitalismo fueron el eco del juicio de Karl Marx sobre la Segunda República como políticamente debilitadora de la misma clase que la fortalecía económicamente. El temor de los propietarios a que las elecciones libres pudieran amenazar sus propiedades y privilegios ha sido cuidadosamente documentado por Thomas Forstenzer, quien observó:

“Habiendo presenciado que, después de décadas de oligarquía, un solo día de lucha callejera fue suficiente para establecer la igualdad política entre todos los franceses, un noble podría haber avizorado tal nacimiento de la igualdad social como una temible posibilidad. La percepción de una izquierda lo suficientemente fuerte como para lanzar una revolución, obtener una victoria en los escrutinios, o incluso continuar ganando adherentes entre las clases más bajas, constituía una amenaza suficiente contra los valores tradicionales como para provocar un desesperado temor social entre las elites" (Forstenzer, 1981: 22).

Los conservadores comprendieron rápidamente que el sufragio masculino universal podía funcionar como un baluarte contra la revolución en vez de constituir un preludio al socialismo. Sus temores sobre la democracia fueron apaciguados por la elección de una mayoría conservadora en la Asamblea Nacional en abril de 1848, la posterior represión de la 
insurrección de junio de 1848 y la elección de un presidente no-republicano, Luis-Napoleón Bonaparte, en diciembre del mismo año. Estas derrotas no detuvieron las actividades electorales republicanas. Después de diciembre de 1848, los republicanos crecieron sostenidamente en fuerza electoral y expandieron su base electoral de las ciudades al campo. En la elección de la Asamblea Legislativa de 1849, los republicanos obtuvieron 180 cargos electos y cerca de un tercio del total de los votos, con una una fuerte penetración en zonas rurales donde nunca antes se había votado por los republicanos. Muchos de los que jugaron un rol clave en la organización de las victorias de 1849, incluyendo treinta diputados electos, recurrieron a las barricadas en junio de 1849, cuando Luis Napoleón violó la Constitución al invadir Roma.

La represión de la insurrección de 1849 fue seguida por nuevas leyes que restringieron las actividades de los clubes (19 de junio) y de la prensa (27 de julio). Esta represión reforzada no condujo a los republicanos a abandonar la estrategia electoral. Los éxitos electorales republicanos rápidamente incitaron un ataque conservador contra el principio más fundamental de la república, el sufragio masculino universal. Las victorias republicanas en las elecciones parciales de marzo de 1850, realizadas para reemplazar a los diputados republicanos implicados en la insurrección de junio de 1849, intensificaron los temores conservadores. El 31 de mayo de 1850, la mayoría conservadora de la Asamblea Nacional respondió aprobando una nueva ley electoral que limitaba los derechos de sufragio. La ley que desmovilizó a 2.7 millones de votantes, o 28 por ciento del electorado nacional, revivió el debate entre los republicanos sobre la viabilidad de la estrategia electoral. Muchos trabajadores socialistas abandonaron la política electoral a favor de sociedades revolucionarias secretas o de las milicias. Ochenta y cuatro diputados republicanos defendieron una estrategia parlamentaria no violenta en respuesta a esta ley. Pero veinticuatro diputados crearon la Nueva Montaña, que no estaba dispuesta a renunciar a la violencia revolucionaria en ausencia del sufragio masculino universal. La Nueva Montaña organizó sociedades secretas que proliferaron en las provincias en 1850 y 1851 (Weill, 1928: 251; Huard, 1978: 109). Aunque comprometidas con el establecimiento de una forma de gobierno parlamentario, estas organizaciones también estaban dispuestas al uso de la violencia revolucionaria para defender la república. Para la elección de 1852, muchos trabajadores socialistas, privados de derechos de ciudadanos, amenazaron con aparecer en la caseta de votación con un rifle en una mano y la papeleta en la otra. Los líderes del Partido Republicano incitaron repetidamente a sus seguidores de clase trabajadora y campesinos a esperar pacientemente las elecciones de 1852, con la esperanza que un triunfo electoral pudiera derribar al gobierno.

La ambivalencia de muchos republicanos respecto a la acción revolucionaria se originaba en un principio republicano, contenido en las Constituciones: el principio de la regla de la mayoría (véase a Offe, 1985, sobre la ley de la mayoría como principio legitimador). Este principio no había 
asegurado una amplia legitimidad entre los republicanos de mediados del siglo XIX porque se mantenía en discusión el asunto fundamental del marco institucional y legal dentro del cual operaría la regla mayoritaria. Los republicanos no coincidían en si las acciones de los representantes electos que violaran el mandato del elector, al desobedecer los principios de la república, como la invasión francesa a Italia en 1849 o la ley electoral de 1850, justificaban el recurso a la acción extraparlamentaria violenta. Cuando los monarquistas ganaron la mayoría en la Asamblea Nacional durante la Segunda República, los republicanos socialistas los vieron como una amenaza a la existencia de la república. Estos dudaron en aceptar la derrota electoral por no haber garantías que sus oponentes aceptaran los fundamentos institucionales de la república, los cuales habían sido originados en las barricadas.

El establecimiento del sufragio masculino universal, en febrero de 1848, no se tradujo en un repentino triunfo de la política electoral como único medio legítimo de expresión de las opiniones políticas. Aunque los republicanos liberales lucharon para que el advenimiento del sufragio significara el fin de una era de revolución, los trabajadores republicanos estaban menos dispuestos a renunciar a las barricadas a cambio de la papeleta de votación. Los republicanos socialistas demostraron inicialmente su voluntad de usar la violencia revolucionaria en un contexto de sufragio masculino universal, durante la insurrección de Rouen de abril de 1848. Cuando los trabajadores socialistas de Rouen recurrieron a las barricadas, después de la derrota del candidato republicano radical Frederick Deschamps, justificaron su insurrección en términos de la defensa de la república. Dada la polarización política y la candidatura de antiguos orleanistas y de partidarios de una nueva restauración borbónica, los republicanos socialistas de Rouen vieron la elección como una cuestión de triunfo o derrota de la república que recientemente había sido establecida por medio de la acción revolucionaria. La insurrección comenzó con una confrontación, el 27 de abril de 1848, entre Guardias Nacionales armados y trabajadores republicanos que se habían reunido frente al edificio municipal para escuchar el anuncio de los resultados electorales (Zévaès, 1927; Archivos Nacionales de Francia: BB30 365, informe del Procurador General Senard, 5 de mayo de 1848). Los trabajadores socialistas de Rouen interpretaron la derrota electoral de Deschamps como un repudio contra la república, lo que estaba en principio garantizado constitucionalmente más que sujeto a la decisión de la mayoría. Los trabajadores parisinos que recurrieron a las barricadas, en junio de 1848, después que la Asamblea conservadora disolviera los Talleres Nacionales, también pensaron que estaban defendiendo la república (Gosses, 1956: 439-58). Cuando los republicanos recurrieron nuevamente a las barricadas en junio de 1849, lo hicieron en defensa de la Constitución. Éste fue también el caso en diciembre de 1851, cuando los republicanos tomaron las armas para resistirse al golpe de Estado de Luis Napoleón y defender la Constitución. En el contexto de la política francesa de mediados del siglo XIX, los medios revolucionarios eran 
compatibles con los términos legalistas. La violencia insurreccional y el constitucionalismo democrático no eran necesariamente contrarios.

El golpe de Luis Napoleón en diciembre de 1851 fue seguido por una intensa represión que, a pesar de preservar el sufragio masculino universal, destruyó temporalmente al Partido Republicano y puso un término al sistema de partidos de la Segunda República. Aunque el gobierno imperial revivió, aquello que muchos republicanos consideraban ser la piedra angular de la democracia, el sufragio masculino universal, destruyó aquel sistema de partidos competitivo que había dado un contenido significativo a las actividades electorales, arrestando o exiliando a los líderes partidarios opositores y restringiendo severamente los derechos de asociación, de reunión y de prensa. Luis Napoleón representó un símbolo ambiguo frente a la democracia. Como descendiente de Napoleón, afirmó la tradición imperial que había difundido las ideas e instituciones republicanas por gran parte de Europa. Como heredero del republicanismo revolucionario, con el respaldo del consentimiento popular, Luis Napoleón preservó el sufragio masculino universal. Sin embargo, rechazó a los partidos políticos como a facciones divisionistas, restringió severamente los derechos de asociación y se apoyó en las presiones administrativas y en el patronazgo estatal, no así en la organización partidaria, para ganar elecciones cuidadosamente manipuladas, incluyendo los plebiscitos a nivel nacional en 1852 y 1870.

Durante el Segundo Imperio (1851-1870), el potencial impacto del sufragio masculino universal fue limitado por medidas que debilitaron al Parlamento y convirtieron a los alcaldes en designados, en vez de electos. Durante la década de 1850, las actividades republicanas cayeron en la clandestinidad como consecuencia de un aparato de policía estatal que hacía cumplir las severas restricciones que pesaban sobre los derechos de asociación, de reunión y de prensa (Payne, 1966). Sociedades conspirativas secretas asumieron un papel más importante en las acciones políticas republicanas. Abstenciones masivas marcaron las elecciones de la década, ya que los trabajadores abandonaron el sufragio como solución a sus problemas. Cuando la estructura de oportunidad política cambió durante los años 1860, los republicanos retomaron las políticas electorales y marcaron asombrosos triunfos en las elecciones municipales en varias grandes ciudades francesas. Las reformas liberales de los años 1860, levantaron las restricciones a los derechos de asociación, reunión y prensa, haciendo posible que los republicanos nuevamente organizaran campañas políticas efectivas. Los trabajadores se presentaron en las mesas de votación en números crecientes para apoyar a los candidatos republicanos durante las elecciones de la década de 1860. Su voluntad de usar la papeleta no fue, sin embargo, una señal de abandono de las formas disruptivas de protesta política.

La visión de los trabajadores republicanos sobre la acción política institucional y rupturista como complementarias, más que contradictorias, es evidente en las actividades electorales al final del Segundo Imperio. 
Cuando el candidato republicano en Toulouse, Armand Duportal, fue estrechamente derrotado en las elecciones legislativas de 1869 por los votos rurales provenientes de los campos circundantes, después de haber ganado por una considerable mayoría en la ciudad de Toulouse, los trabajadores socialistas que habían acudido a las mesas de votación en grandes cantidades se tomaron las calles para protestar. El anuncio de los resultados de la elección dio inicio a tres días de vandalismo marcados por múltiples confrontaciones entre los manifestantes y la policía y docenas de arrestos (Archivos Nacionales de Francia: BB18 1766). Durante la elección de mayo de 1869 en Saint-Etienne, los trabajadores se reunieron en las calles así como en los locales de votación para apoyar al candidato republicano Frederick Dorian. Aunque las mujeres no estaban invitadas y no asistieron a los mítines de Dorian, ellas permanecieron afuera, en la calle, con sus niños y alentaron a Dorian cuando entró y abandonó el edificio. El comisario de policía describió la escena fuera de un mitin político como "una especie de charivari, con mujeres golpeando cucharas contra cucharas salseras que habían traído para comer su sopa en la calle". Las campañas electorales aún no se habían convertido en asuntos serios; ellas le daban la oportunidad a los excluidos del sufragio para expresar públicamente sus sentimientos políticos con estridentes formas tradicionales de acción colectiva. De acuerdo a los reportes de la policía, activistas del partido republicano se instalaban a las salidas de los mítines electorales de Dorian para recordarle a los trabajadores que salían de las reuniones que eran "hombres de orden" (Archivos municipales de St. Etienne: 7k1, Informes del comisionado central de policía del 5, 16-18 de mayo de 1869). Durante la campaña, trabajadores republicanos hicieron callar al candidato realista Rochetaillé cuando apareció en el vecindario de Montaud e interrumpieron un encuentro electoral de sus partidarios. Esto motivó a Rochetaillé a cancelar sus siguientes encuentros electorales para así evitar una confrontación violenta. Dorian hizo campaña como "libre pensador", atacando a la Iglesia y al clero y abogando por una educación gratuita y obligatoria. Después de que Dorian ganara la elección, consiguiendo el $62 \%$ de los votos, sus partidarios celebraron el triunfo en la tarde del 24 de mayo, atacando el colegio jesuita de Saint-Michel, rompiendo varios vidrios y prendiendo fuego al cuarto del cuidador. Para estos trabajadores republicanos, las manifestaciones y las protestas callejeras violentas eran una extensión natural de la lucha en las urnas.

Después de la derrota francesa en la guerra franco-prusiana, en septiembre de 1870, las políticas revolucionarias adquirieron una importancia creciente. La derrota en la guerra y el reestablecimiento de la república en una situación de crisis política y económica incentivó una renovación de la acción política participativa y un resurgimiento de las estrategias revolucionarias. En un contexto de guerra y crisis de régimen, en numerosas ciudades los trabajadores urbanos tomaron las armas y se abrieron camino dentro de las milicias de la Guardia Nacional, las cuales los habían excluido anteriormente. Los trabajadores socialistas formaron 
clubes revolucionarios y organizaron manifestaciones populares diseñadas para ejercer presión sobre las autoridades locales para que aceptaran medidas revolucionarias, incluyendo una movilización masiva de toda la población (levée en masse) para expulsar a las tropas prusianas del suelo francés 5 . La elección de una Asamblea Nacional controlada por los realistas a principios de 1870 alentó a los republicanos a abrazar la acción revolucionaria para defender la república. En 1871, tal como en 1848, los republicanos revolucionarios se negaron a aceptar cualquier veredicto de la regla de la mayoría que amenazara la existencia de la República. Los republicanos proclamaron las comunas insurrectas, en marzo de 1871, en las ciudades más grandes de Francia, incluyendo París, Lyon, Marsella, Nimes, Toulouse, Saint-Etienne y Narbona (Gaillard, 1971). Los comuneros justificaron su recurso a la insurrección como defensa de la nueva república, la que estaba siendo amenazada por una Asamblea Nacional controlada por los monarquistas en Versalles. Su llamado a la revolución no implicaba, sin embargo, un rechazo a las políticas electorales. Una de las primeras acciones de los comuneros revolucionarios de París fue realizar elecciones municipales.

La represión de las comunas revolucionarias de 1870-71, cuando murieron más de 25.000 insurgentes (Edwards, 1973), marcó un momento crucial en la historia del republicanismo francés. Preparó el escenario para la derrota de los elementos socialistas al interior del Partido Republicano, la institucionalización de una forma de Estado republicana conservadora y el triunfo de las nociones liberales de la representación y la democracia entre los republicanos ${ }^{6}$. La democracia directa de mandato imperativo, siendo respaldada por los comuneros revolucionarios, fue desplazada por la visión liberal de la democracia representativa, la cual estaba contenida en la Constitución republicana de 1875 y se volvió dominante al interior de los círculos republicanos hacia la década de 1880 (Huard, 1985: 138; Nicolet, 1982: 413-15). Luego de la derrota de las comunas, los acuerdos para asegurar la república y prevenir el restablecimiento, ya sea de una monarquía o de un régimen militar autoritario, llevaron a los republicanos a rechazar elementos claves de la tradición revolucionaria francesa. Muchos de los principios políticos que habían dominado el republicanismo de mediados del siglo XIX fueron infringidos por las medidas de 1875 (Nicolet, 1982: 166, 424). Los republicanos aceptaron con resistencias las disposiciones institu-

\footnotetext{
5. La levée en masse alude al precedente de la Revolución Francesa cuando, en 1792-93, los batallones voluntarios liderados por nuevos comandantes, no por los generales del Antiguo Régimen, expulsaron a los invasores extranjeros de Francia. El gobierno revolucionario que organizó la levée en masse se convirtió en el régimen del Comité de Salud Pública de Robespierre y los ejércitos revolucionarios se transformaron en los agentes del Terror. 6. Sin embargo, los trabajadores continuaron respaldando el mandato imperativo como una manera de asegurar que los representantes continuaran respondiendo a las demandas de los trabajadores. En las elecciones de los consejos de arbitraje laboral (conseils de prud'hommes), por ejemplo, los líderes sindicales hacían cumplir su mandato a los representantes por medio de la firma de una carta de renuncia anticipada, la que era usada en caso de que ellos violaran sus mandatos (Olszak, 1987).
} 
cionales -un Ejecutivo fuerte y una legislatura bicameral con una Cámara Alta- a las que se habían opuesto acérrimamente en 1848. El abandono de los republicanos franceses de las acciones políticas "antiinstitucionales" preparó el escenario para los ulteriores cuestionamientos socialistas y anarcosindicalistas de los límites de la democracia liberal y para la formación de un partido de clase trabajadora durante las últimas décadas del siglo. La política institucionaliza fue cobrando una aceptación firme entre los republicanos sólo después de que el republicanismo fuera transformado y se desprendiera, ideológica e institucionalmente, de sus estrechas conexiones previas con la visión participativa de la democracia y con el socialismo.

Durante mediados del siglo XIX, las cambiantes circunstancias políticas, especialmente el ritmo de la represión, moldearon el atractivo cambiante de las estrategias alternativas, las que fueron sujeto de acalorados conflictos entre los republicanos. Pero cambios en la estructura institucional del Estado, o en el equilibrio de poderes del régimen, o en el grado de apertura del sistema político según niveles variables de represión, no pueden dar cuenta por sí solos de la voluntad de los republicanos de arriesgar sus propias vidas en las barricadas, o de soportar privaciones con la esperanza que sus representantes electos pudieran finalmente dar respuesta a sus demandas. Las ideologías de la representación fueron también determinantes críticas de las decisiones estratégicas, que le permitieron, o impidieron, al pueblo reconocer y apoderarse de oportunidades para actuar colectivamente. Por ejemplo, el derrocamiento del régimen imperial y el establecimiento de una república en 1870 no fue simplemente la consecuencia inevitable de una estructura de oportunidades políticas alterada por las crisis económica y política. Fue también el resultado de una ideología participativa de representación que alentó al pueblo a seguir sus sueños, miedos y aspiraciones mediante formas culturalmente específicas, tomándose las calles para forzar a los renuentes representantes republicanos electos a proclamar la República.

\section{Conclusión: Organización, estrategia e ideología}

El estudio histórico de los movimientos sociales destaca la dificultad de distinguir claramente diferencias entre los comportamientos políticos no-convencionales e institucionalizados, y entre los movimientos sociales y los partidos políticos, en contextos históricos no caracterizados por el predominio de la acción política basada en la asociación y en una cultura política liberal-democrática7 ${ }^{7}$ En contextos históricos donde

7. La fluidez del límite entre partidos y movimientos es también evidente en ciertos contextos políticos contemporáneos donde los supuestos permanecen abiertos al cuestionamiento de los partidos políticos de izquierda. Esta fluidez es estudiada en el trabajo de Sydney Tarrow (1990) sobre los "nuevos movimientos sociales" en Italia, que ilustra el surgimiento de los movimientos sociales de los años sesenta y setenta como insurgencias al interior del sistema de partidos: “Bajo la apariencia superficial de una oposición rígida 
el derecho a voto ha sido limitado, las nociones de representación cuestionadas, donde los derechos de asociación son frágiles, donde las capacidades del Estado para hacer concesiones así como el conflicto institucionalizado son limitados y donde las políticas locales están basadas en la comunidad más que en la asociación, las dicotomías de la teoría política contemporánea se vuelven problemáticas. En la Francia de mediados del siglo XIX, distinguir entre movimientos y partidos en términos de estrategias electorales y no-electorales es difícil, dado que los partidos políticos iniciales a veces se aventuraban fuera de la arena electoral y combinaban la acción política colectiva destructiva con campañas para elegir candidatos. En este contexto histórico, la cercana conexión entre las protestas políticas y las políticas electorales implicaban una escurridiza y fluida, más que fija, frontera entre los movimientos sociales y los partidos políticos. El Partido Republicano francés de mediados del siglo XIX, si bien competía por cargos electos, simultáneamente adoptaba tácticas rupturistas, no-convencionales y, a veces, ilegales, combinando formas aparentemente contradictorias de acción política colectiva. Sólo después del establecimiento de una cultura política liberal democrática y del ajuste institucional de finales del siglo XIX, las dicotomías de la teoría política contemporánea -por ejemplo, la protesta versus el voto- se convirtieron en un supuesto ampliamente compartido entre los republicanos franceses. Una perspectiva histórica de los movimientos sociales hace que el límite que separa la acción política institucionalizada de la antiinstitucionalizada aparezca no tan natural o inevitable, sino como el producto histórico del triunfo de una forma organizacional particular -los partidos políticos- y una visión particular de la representación política.

Una perspectiva histórica nos permite identificar más claramente qué es exactamente lo nuevo en los así llamados movimientos sociales y entonces evitar el peligro de exagerar la novedad de los movimientos contemporáneos (véanse Tarrow, 1989; Calhoun, 1993). Los teóricos de los movimientos sociales a veces conciben los cuestionamientos contemporáneos a la legitimidad de los partidos políticos, por los defensores de una democracia participativa, como un producto reciente de los nuevos movimientos sociales que cuestionan las premisas de las concepciones liberales de la representación y de la democracia. Este estudio sobre el republicanismo francés de mediados del siglo XIX nos recuerda que el cuestionamiento de los demócratas comprometidos acompañó la creación de las instituciones liberal-democráticas. Una rama del movimiento republicano francés de mediados del siglo XIX elaboró una visión alternativa de la democracia participativa que desafió los supuestos de las instituciones liberales-democráticas de la representación, incluyendo su

entre los indómitos, espontáneos y antipartidistas nuevos movimientos de los años sesenta y setenta, y las formales, antiguas, instituciones conservadoras del sistema de partidos existía... un conjunto de relaciones mucho más complejas e interpenetradas" (Tarrow, 1990: 271). 
definición restrictiva de la política y su rígida separación entre la acción política institucionalizada y antiinstitucional.

Este estudio también discute la noción según la cual las leyes de desarrollo enraizadas en dinámicas organizacionales producen inevitablemente una formalización progresiva de los movimientos. La historia del republicanismo francés durante la mitad del siglo XIX sugiere que la formalización siguió un camino muy irregular. Antes de 1848, la organización republicana siguió siendo altamente informal en su forma, como resultado del carácter local de la política francesa. Una orientación hacia formas institucionalizadas de acción política, como las elecciones, no requería altos niveles de formalización, dado que los republicanos podían efectivamente perseguir metas electorales usando a los centros de sociabilidad popular como vehículos de movilización política. Después de 1848, la ampliación del sufragio masculino universal y de las libertades políticas, así como también la nueva geografía de la representación, fomentaron el desarrollo de una organización más formal. Pero fue la primera elección nacional de presidente la que incentivó la creación inicial de una organización altamente centralizada y formal del Partido Republicano. La represión de 1849-51 destruyó esta organización y llevó a las actividades republicanas a la clandestinidad, reforzando el carácter local, descentralizado y no jerárquico del republicanismo francés propio de sus inicios. Pese al sufragio masculino universal, a las elecciones nacionales y al rápido desarrollo de la infraestructura de transporte y comunicaciones durante el Segundo Imperio (1851-70), el republicanismo continuó enraizado en redes locales de sociabilidad informal. A través de la década de 1850, la intensa represión llevó a los republicanos a la clandestinidad y temporalmente eliminó los remanentes de la organización formal y nacional del partido. La atenuación de las restricciones al derecho de reunión, de asociación y de prensa estimuló, durante los años 1860, el desarrollo de una organización más formal entre los republicanos, especialmente durante las elecciones nacionales de 1869. En conclusión, a través de la mitad del siglo XIX, el republicanismo francés permaneció organizado informalmente, a pesar de sus oscilaciones entre una actividad política más o menos formalmente organizada, en gran parte como respuesta a los variables niveles de represión política y a las cambiantes reglas electorales.

El compromiso ideológico de los republicanos socialistas con la visión participativa de la democracia privilegió la política local e impidió la formalización, pero los desarrollos organizacionales fueron más un producto de factores institucionales que de factores ideológicos. La ideología no era un factor importante en la inhibición de la formalización, ya que la mayoría de los republicanos reconocía las virtudes de una organización más formal; la mayor capacidad de coordinación entre grandes superficies incrementaba la habilidad para ganar elecciones no-locales, una mayor capacidad para asegurar ganancias duraderas y una acentuada capacidad para resistir la infiltración gubernamental durante los períodos de represión. Para los liberales, un fuerte compromiso con el Esta- 
do de Derecho se traducía en un respaldo a las reglas organizacionales más formales; en cambio, la aspiración de los socialistas a una mayor participación popular en la nominación de los candidatos del partido los alentó a apoyar reglas formales para limitar el poder informal de los notables locales. El localismo y la diversidad organizacional, no la oposición ideológica contra el principio de reglas formales, impidieron la formalización. Los conflictos ideológicos entre los republicanos se centraron en las discrepancias sobre las opciones estratégicas, más que sobre las alternativas organizacionales.

Las estrategias republicanas de lucha por el poder, que oscilaban entre la acción política revolucionaria y la acción política electoral, estaban estrechamente conectadas con los conflictos ideológicos sobre el significado de la representación y de la democracia. Aunque comprometidos con la república y los procesos electorales, los republicanos socialistas justificaron sus acciones ilegales en los términos de una ideología democrática participativa que legitimaba las posturas insurrectas frente a quienes violaran sus mandatos como representantes del pueblo. Reforma y revolución no eran dicotomías para los republicanos socialistas, los que simultáneamente legitimaban ambas estrategias, dependiendo de circunstancias políticas de rápida variación. Las estrategias republicanas de lucha por el poder, además de ser oscilantes, fueron configuradas por las mismas fuerzas que influyeron el proceso de formalización, incluyendo niveles cambiantes de represión política y cambiantes leyes electorales, pero también surgieron de la lucha entre los republicanos sobre el significado de la democracia. Los republicanos cambiaron sus estrategias en función de oportunidades políticas inestables, especialmente respecto al nivel y a la probabilidad de la represión. Pero las diferentes estrategias políticas fueron afectadas tanto por dinámicas ideológicas como por dinámicas institucionales.

La formalización y la institucionalización no siguieron trayectorias paralelas debido a dinámicas diferentes que impulsaron los dos procesos. La intensa represión que marcó la cambiante estructura de oportunidad política fomentó tanto la acción política formal como la acción política antiinstitucional. Cambios hacia una mayor formalización no produjeron, sin embargo, automáticamente la institucionalización. El republicanismo mantuvo su carácter antiinstitucional incluso en períodos de creciente formalización, porque la mayoría de los republicanos no veía a las actividades electorales y a las acciones políticas no-convencionales como necesariamente contradictorias. Para los republicanos socialistas, la organización formal podía ofrecer la posibilidad de una mayor coordinación y ganancias políticas duraderas, pero ello no significó una voluntad de abandonar las formas rupturistas y no-convencionales de acción política colectiva, justificadas por una visión participativa de la democracia y por la noción de mandato imperativo. La adopción de estrategias electorales, durante la década de 1840, no fue el resultado de la burocratización al interior del movimiento republicano sino el resultado de preferencias -de las discutidas estrategias escogidas por los líderes del 
partido- basadas en las experiencias con estrategias o compromisos ideológicos previos.

La adopción de estrategias que priorizaban la acción política electoral (i.e. institucionalizada) no condujo a una organización crecientemente formal, con características tales como un equipo remunerado, cuotas de membresía y líderes formalmente elegidos. Incluso cuando los republicanos rechazaron las políticas revolucionarias a favor de una estrategia electoral, mantuvieron su estructura organizacional informal y descentralizada. Esta estructura estaba determinada por una variedad de factores, incluyendo la persistencia del localismo y la geografía de la representación, no sólo por consideraciones estratégicas.

A largo plazo, la institucionalización y la formalización fueron de la mano, pero esta conexión no era el producto inevitable de una lógica de desarrollo. Fue el resultado, durante las últimas tres décadas del siglo XIX, del establecimiento de una cultura política liberal-democrática y de una configuración institucional que encarnó un concepto específico del significado de la representación política. El triunfo de la noción liberal de la democracia deslegitimó, entre los republicanos franceses, a las formas directas de acción política colectiva. En este contexto histórico particular, la institucionalización estimuló rápidamente la formalización del republicanismo francés. En un contexto liberal-democrático existe un vínculo necesario entre la búsqueda de una estrategia electoral y la formalización, ya que la responsabilidad de los representantes ante los electores requiere formalización, dada la ausencia de mecanismos de intervención y de control popular. El surgimiento histórico relativamente reciente de este contexto y su inaplicabilidad contemporánea a gran parte del globo, sugiere la necesidad de historiar nuestras teorías de los movimientos sociales. Esto no significa una negación historicista de la posibilidad de abstracción a través del tiempo y del espacio. En cambio, ello implica la necesidad de situar nuestras teorías en el tiempo y en el espacio y requiere ser más explícitos sobre de la dependencia de las regularidades respecto de los contextos históricos.

\section{Bibliografía}

Agulhon, Maurice. 1982. The Republic in the Village. Cambridge. Cambridge University Press.

Agulhon, Maurice. 1984. “Working Class and Sociability in France before 1848". En Thane, Pat, Crossick, Geoffrey, Floud, Roderick, eds. Power of the Past. Cambridge. Cambridge University Press: 37-66.

Amman, Peter. 1975. Revolution and Mass Democracy. Princeton. Princeton University Press.

Baker, Keith Michael. 1987. "Representation". En Baker, Keith Michael, ed. The Political Culture of the Old Regime. Oxford. Pergamon: 469-491.

Bastid, Paul. 1954. Les institutions politiques de la monarchie parlementaire française (1814-1848). Paris. Recueil Sirey. 
Berenson, Edward. 1984. Populist Religion en Left-Wing Politics in France 1830-1852. Princeton. Princeton University Press.

Birch, Anthony H. 1971. Representation. New York. Praeger.

Calhoun, Craig. 1993. "New social Movements of the Early $19^{\text {th }}$ Century". Social Science History 17: 385-427.

Cloward, Richard, Piven, Frances, 1977. Regulating the Poor. New York. Pantheon.

Clawson, Mary Ann. 1989. Constructing Brotherhood. Princeton. Princeton University Press.

Edwards, Stewart. 1973. The Paris Commune 1871. New York. Quadrangle.

Forstenzer, Thomas. 1981. French Provincial Police and the Fall of the Second Republic. Princeton. Princeton University Press.

Gaillard, Jeanne. 1971. Communes de province, commune de Paris 1870-1871. Paris. Flammarion.

Gamson, Willam A. 1975. The Strategy of Social Protest. Homewood. Dorsey.

Halevi, Ran. 1985. “Modalités, participation et luttes électorales en France sous l'Ancien Régime". En Gaxie, Daniel, ed. L'explication du vote. Un bilan des études électorales en France, Paris. Presses de la Fondation Nationale des Sciences Politiques: 85-105.

Huard, Raymond. 1978. "La genèse des partis démocratiques modernes en France". La pensée 201: 96-119.

Huard, Raymond. 1982. La préhistoire des partis: le mouvement républicain en Bas-Languedoc. Paris. Presses de la Fondation Nationale des Sciences Politiques.

Huard, Raymond. 1985. “Comment apprivoiser le suffrage universel?". En Gaxie, Daniel, ed. L'explication du vote. Un bilan des études électorales en France, Paris. Presses de la Fondation Nationale des Sciences Politiques: 126-148.

Jenkins, J. Craig. 1977. "Radical Transformation of Organizational Goals". Administrative Science Quaterly 22: 568-585.

Jenkins, J. Craig. 1983. "Resource Mobilization Theory and the Study of Social Movements". Annual Review of Sociology 9: 527-553.

Jenkins, J. Craig. 1985. The Politics of Insurgency. New York. Columbia University Press.

Lang, Kurt, Lang, Gladys. 1961. Collective Dynamics. New York. Crowell.

Latta, Claude. 1980. Un républicain méconnu: Martin Bernard. Saint-Etienne. Centre d'Etudes Foreziennes.

Lequin, Yves. 1984. Les citoyens et la démocratie. Paris. Armand Colin.

Major, J. Russel. 1960. The Deputies of the Estates General of Renaissance France. Madison. University of Wisconsin Press.

McCarthy, John, Zald, Mayer. 1973. The Trends of social Movements in America. Morristown. General Learning.

McCarthy, John, Zald, Mayer. 1977. "Resource Mobilization and Social Movements". American Journal of Sociology 82: 45-76.

Melucci, Alberto, ed. 1981. Altri codici. Bologna. Il Mulino. 
Merriman, John. 1978. The Agony of the Republic. New Haven. Yale University.

Nicolet, Claude. 1982. L'idée républicaine en France. Paris. Galimard.

Oberschall, Anthony. 1973. Social Conflict and Social Movements. Englewood Cliffs. Prentice-Hall.

Offe, Claus. 1985. "Legitimation through the Majority Rule?". En Keane, John, ed. Disorganized Capitalism. Cambridge. MIT Press: 259-299.

Olszak, Norbert. 1987. "Les conseils des prud'hommes: un archétype judiciaire pour le mouvement ouvrier?". Le Mouvement Social 141: 101-119.

Payne, Howard. 1966. The Police State of Louis Napoleon Bonaparte. Seattle. University of Washington Press.

Ponteil, Félix. 1968. Les classes bourgeoises et l'avènement de la démocratie, 1815-1914. Paris. Albin Michel.

Soboul, Albert. 1975. The French Revolution, 1787-1799. Traducido por Alan Forrester y Colin Jones. New York. Vintage.

Soule, Claude. 1962. "La notion historique de représentation politique". Politique 6: 17-32.

Soule, Claude. 1968. Les Etats Généraux de France (1302-1789). Paris. Heulé.

Tarrow, Sidney. 1989. "Struggle, Politics, and Reform: Collective Action, Social Movements, and Cycle of Protest. Western Societies Program". Occasional Paper 21. Ithaca. Cornell University.

Tarrow, Sidney. 1990. "The Phantom at the Opera: Political Parties and Social Movements of the 1960s and the 1970s in Italy". En Dalton, Russel J., Kuechler, Manfred, eds. Challenging the Political Order: New Social Movements in Western Democracies. Cambridge. Polity: 251-273.

Traugott, Mark. 1978. "Reconceiving Social Movements". Social Problems 26: 38-49.

Tudesq, André Jean. 1964. Les grands notables en France. Vol 2. Paris. Presses Universitaires de France.

Turner, Ralph H., Killian, Lewis M. 1987. Collective Behaviour. 3ed. Englewood Cliffs. Prentice-Hall.

Vigier, Philippe. 1973. "Elections municipales et prise de conscience politique sous la monarchie de Juillet". En La France au XIXe siècle. Mélanges offerts à Charles Hippolyte Pouthas. Paris. Publications de la Sorbonne: 276-286.

Weill, Georges. 1928. Histoire du parti républicain en France. Paris. Ressources.

Zévaès, Alexandre. 1927. "La lutte des classes à Rouen en Avril 1848". La Révolution de 1848 24: 214-215. 